\title{
A Welding Capability Assessment Method (WCAM) to support multidisciplinary design of aircraft structures
}

\author{
Julia Madrid $^{1}\left({ }^{1} \cdot\right.$ Anders Forslund $^{1} \cdot$ Rikard Söderberg $^{1} \cdot$ Kristina Wärmefjord $^{1}$ \\ Steven Hoffenson $^{2}$. Johan Vallhagen ${ }^{3}$. Petter Andersson ${ }^{3}$
}

Received: 11 July 2017 / Accepted: 31 August 2017 / Published online: 16 September 2017

(C) The Author(s) 2017. This article is an open access publication

\begin{abstract}
Designing aircraft engines is a complex process in which requirements from multiple disciplines need to be considered. Decisions about product geometry and tolerances to achieve optimized aerodynamics, product life and weight can affect the manufacturing process. Therefore, providing information to designers about process capabilities is necessary to support design exploration and analysis. In this paper, the authors propose the Welding Capability Assessment Method (WCAM) as a tool to support the systematic identification and assessment of design issues related to product geometry critical to the welding process. Within this method, a list of potential failure modes during welding is connected to specific design parameters. Once the critical design parameters have been identified, quantitative methods are proposed to calculate tolerances to reduce the likelihood of welding failures. The application of this method is demonstrated through an industrial case study where a combination of interviews and welding simulations is used to study the welding capability of a number of product geometries. This method represents an advancement from traditional qualitative guidelines and expert judgments about welding difficulties towards a more quantitative approach, supporting virtual design.
\end{abstract}

Keywords DFM - DFA · Design for welding - Design for quality $\cdot$ Process capability · Variation management . Tolerancing

Julia Madrid

julia.madrid@chalmers.se

1 Department of Industrial and Materials Science, Chalmers Univeristy of Technology, Gothenburg, Sweden

2 Stevens Institute of Technology, Hoboken, NJ, USA

3 GKN Aerospace Engine Systems, 4681 Trollhättan, Sweden

\section{Introduction}

Jet engine suppliers have adopted fabrication as a technique for reducing the weight of engine components, improving fuel consumption and reducing emissions [1]. Some of these fabricated components employ welding as the main assembly technique. Welding is a complex operation during which the quality of the welded structure is affected by many factors, including welding process parameters, the weld joint geometry, fixture designs, product form division and product geometry [2].

Furthermore, jet engines are comprised of components with complex geometries, closely linked to product performance. These components can be defined as integrated products in which multiple functions are satisfied by one single structure [3]. A small change of the geometry would affect the aerodynamic performance, product life and weight [4]. Therefore, tight tolerances are applied to these products, limiting manufacturing options.

Certain decisions about product structure, geometry and tolerances, made during the design process, will affect the outcome of the welding, resulting in geometrical variations and metallurgical defects [4]. This causes rework at the manufacturing floor and redesign loops, delaying projects and increasing costs, which translates to customer dissatisfaction. Therefore, there is a need to understand the impact of product geometry on the manufacturing process. Anticipating welding capabilities during the exploration and analysis of the design space would reduce the amount of production rework, costs and time.

Design for Manufacturing (DFM) and manufacturability assessment methods support design evaluation by making available information about the capabilities and limitations of the different manufacturing methods [5,6]. With manufacturing knowledge at hand, designers can select processes 
and evaluate design alternatives given available manufacturability criteria. Much research has been conducted within the field of DFM since it was first introduced in the 1980s [7]. Nevertheless, the consideration of welding processes within the traditional Design for Manufacturing field has not been extensive. Other processes such as machining, injection modeling, casting or stamping have had greater prevalence [8-11].

However, in recent literature, studies on Design for Welding have brought the areas of Material Science and Welding Engineering together with Design Engineering and more specifically DFM. Among this literature, two main fields can be distinguished for their contributions: Engineering Design and Welding Engineering. Within the first field, researchers contribute to Engineering Design by presenting DFM selection tools and methodologies for evaluating alternative designs, materials and welding processing options at the early design stages [2,12-15]. All these DFM methods are created on the basis that manufacturability and cost criteria are known. They rely on the existence of DFM rules and guidelines that contain knowledge about the limitations of the different materials and welding processes in relation to certain product geometries. However, this information about production capabilities is rarely available [16]. In addition, the criteria these methods use to rank the alternative welding methods is based on expert judgment, as problems on welding are difficult to judge based on experience. Within the second field, Welding Engineering, numerous studies have been found with a focus on the design of the welding process. Kwon et al. [17] provided DFM support so that the design of the weld joint, weld bead geometry and welding parameters are performed concurrently. Through design of experiments (DOE), Widener et al. [18] investigated the window for welding process parameters in combination with tool design in order to achieve certain weld morphology and microstructure. Moreover, welding simulations have been used in many studies to design the welding sequence [19] or optimize welding parameters for minimum deformation. In these studies, the focus is on the parameters of the welding operation itself, and how to fine-tune them (welding parameters window). However, this process is generally limited to single nominal product geometries. Geometry variants are neither tested nor compared. Thus, no support is provided on how the different product geometries, constituting the design space, affect the output of the welding process.

Industry aligns with academy in this case. During preproduction phases, manufacturing analyses are carried out for an already selected single nominal geometry. However, a range of possible geometries are not analyzed with regards to manufacturing. This leads to a lack of awareness of production capabilities with respect to welding, since this manufacturing method output is highly dependent on product geometry. A slight change in product geometry can result in a totally different welding outcome. The lack of data and information about production capabilities hinders the application of DFM approaches and manufacturability assessments within the design space exploration process where a number of design variants are considered potential design candidates. Therefore, an important aspect when building DFM selection tools and methodologies for designers is the provision of clear guidance in identifying and quantifying the important design issues that affect manufacturing.

Scope of the paper In this paper, a method is proposed to identify and assess geometrical design parameters that affect welding outcomes, thus compromising product quality and cost. The aim is to provide designers with support when exploring and analyzing the design space concerning welding capabilities, building reliable capability databases. While fully virtual design analysis is not currently possible for welded structures, this method presents a basis for developing "interactive engineering rules" (if $X$ then $Y$ ) to support the automatized search of solutions within a design space according to know-how, specialized information and capitalized knowledge about welding capabilities. Such a framework for interactive analysis of welding capabilities presenting the relevant design issues would support concurrent development of the design and welding processes earlier in the product development process, connecting welding specialists with designer specialists and supporting virtual and interactive design.

The focus of this paper has been on high performance and integrated products that are fabricated using welding.

Section 2 presents a review of the state-of-the-art of DFM from the perspective of aerospace welded products. In Sect. 3 , the authors propose a method to systematically identify the design parameters critical to the welding process that need to be studied and the means by which these can be assessed to ensure product quality. In Sect. 4, the method is presented in an industrial context. Welding simulation combined with interviews have been chosen as a mixed method approach to assess the welding capabilities for different design variants. Coming sections cover discussion and conclusions.

\section{Background}

This section presents a review of previous work in fields relevant to the method proposed in this paper. First, the authors introduce the multidisciplinary design context for aerospace products. Next is a review of Design for Assembly (DFA) and DFM methods, in which the authors identify differences between the types of product and manufacturing processes used in the DFM and DFA methods reviewed, in particular with respect to welded aerospace components. One main 
difference is the evaluation criteria which need to shift from cost and time towards quality. Based on the above, in the last part of the background (Sect. 2.3), the authors review ways of modeling product quality in the light of manufacturing processes.

\subsection{Design space exploration in Multidisciplinary Design (MDD)}

The design of aircraft engines involves expertise within various disciplines, including aerodynamics, mechanical engineering and manufacturing. Requirements from multiple engineering disciplines must be traded off against target cost and customer value. This situation has motivated the increased adoption of parameterized product models together with multidisciplinary optimization techniques. Different methods and simulation tools are employed to find the optimal value of each design parameter in order to fulfill technical requirements [20].

Furthermore, in early phases, designers must account for uncertainties in the requirements due to the large number of different partners involved in the design process, and the complexity of the engine system. To approach the uncertainty and complexity, requirements are defined in ranges, with a set of possible solutions, referred to as Set-Based Design (SBD) [21]. In SBD, a broad set of design variants is considered and analyzed. This set of variants is narrowed down as the detailed requirements are specified and knowledge about the feasibility of the different solutions is generated.

In recent years, multidisciplinary design (MDD) has progressively benefitted from advancements in computer performance and statistical analysis methods for design space exploration [22]. The automation capabilities within computer-aided design (CAD) software have improved, enabling design engineers to automatically generate a large number of different design variants [20]. These models can be assessed from the perspective of many disciplines and there are significant achievements in automated analysis within Mechanical Engineering and Computational Fluid Dynamics (CFD) [Ansys Workbench, Hyperworks, Siemens Advanced Simulation]. However, the assessment of manufacturing capabilities based on CAD geometry is, if possible, mostly limited to interactive and manual analysis of a single design. There is no automated assessment that can be used, where the need to cover an extended number of design variants is the greatest. One of the reasons is the lack of manufacturing capability data and quantitative data to perform optimization and evaluate trade-off alternatives $[15,16]$.

\subsection{DFA and DFM}

The core principles of Design For Assembly (DFA) and Design for Manufacturing (DFM) were established in the 1980s $[7,23]$ and redefined in the 1990s [6,9-11], and subsequent research related to DFA and DFM builds on those principles. Much of the recent work focuses on providing computer support by using expert systems and KnowledgeBased Engineering (KBE) [14,24-27].

In broad terms, traditional DFA and DFM methods can be classified in two main groups: Qualitative methods composed of guidelines and heuristic illustrations, and quantitative methods for analyzing design alternatives based on cost and time criteria.

In the field of qualitative DFA methods, Andreasen et al. [23] and Pahl and Beitz [28] developed guidelines that include graphical representations of good and bad practices to support designers in creating easy-to-assemble designs.

Notable contributions to qualitative DFM methods have been made by Bralla, Poli and Swift et al. [9-11] . Their handbooks provide an understanding of the technical capabilities and limitations of specific manufacturing processes. These guidelines were initially produced with mature production technologies in mind, such as machining processes, injection modeling, casting or stamping. Other authors, such as Swift et al. [10] and Bralla [11], have added DFM guidelines for a variety of joining processes, providing an overview and description of the joining processes and equipment. However, the information they contain about welding is vague with no further content than the welding handbooks can provide $[29,30]$. Common examples of welding guidance found among DFA and DFM guidelines include: "design parts to give access to the joint"; "distortion can be reduced by designing symmetry in parts"; "design simple or straight contours", "avoid intersecting weld seams" and "avoid joints" [10,11,23,28].

In the late 1980s, the basis of quantitative DFA methods was established by the Boothroyd Dewhurst DFA method [7] and the Lucas DFA procedure [31]. These methods base redesign improvements on simplifications of the product structure by reducing the number of parts, thus reducing assembly time. The different product concept alternatives are evaluated based on assembly difficulty and assembly time. Thereafter, systematic DFM methods emerged after the successful implementation of DFA [6]. DFM was intended to be applied at the part design level, after DFA had addressed the product structure design level. In a first step, DFM methods intend to assist the manufacturing process and material selection, and in a second step, they seek to improve the design to optimize manufacturing costs.

Traditional DFM methods are those assessing partmanufacturing difficulties. Therefore, the focus is on optimizing the design for individual production processes, such as casting, stamping, injection molding and machining processes. Cost estimation models have also been developed as DFM quantitative tools to evaluate manufacturability $[6,9]$. Some of these methods are feature-based evaluation tools. 
Cost indices are provided for processing the different features using parametric models and a library of manufacturing knowledge bases. Although DFM has traditionally been focusing mainly on part forming processes with regard to welding, Schreve et al. [32] also presented a DFM cost model for tack welding. This cost model uses a times and rates approach but does not focus on output quality.

In the methods described above, the type of products in which DFA and DFM are usually applied are those that can be complex in geometry and that contain large numbers of parts. However, in these products, geometry is not highly linked to functionality. This fact allows easy geometrical modifications to solve manufacturing difficulties, as well as product structure modifications to solve assembly difficulties. These actions are aimed at reducing time and cost during production.

Nevertheless, as mentioned in the introduction, welded aircraft structures are products made of geometries closely linked to functionality. Thus, manufacturing variation in key product characteristics becomes a critical issue. Therefore, for this type of application, producibility criteria cannot solely rely on the time and cost spent during the manufacture and assembly but also on the quality built into the product, as suggested by the authors in previous studies $[33,34]$. The objective then becomes to reduce quality-related failures during production, thereby minimizing rework costs.

Under the umbrella of quality, recent research in the area of variation management has been focusing on reducing quality failure and related costs $[15,35,36]$. Subramaniam et al. [37] presented an approach in which producibility metrics have been extracted from defect analysis or failure analysis of the manufacturing process. Their approach focuses on producibility problems that arise due to part geometries. However, this approach only covers forming processes, such as extrusion, injection molding, casting, and machining processes but not welding. Even so, their research has provided significant inspiration to the authors in developing the method proposed in this paper.

\subsection{Modeling product quality creation during the manufacturing process}

Product quality is built into the product throughout the manufacturing process. The set of operations within a manufacturing process transform a product from raw material to a final shape, material and properties. Madrid et al. [34] introduced a model to describe product quality creation during the manufacturing process. This model was inspired by the Theory of Technical Systems (TTS) [38] and by manufacturing variation models $[35,39]$.

Figure 1a shows a model of a manufacturing operation within the manufacturing process based on the Theory of Technical Systems (TTS). Hubka and Eder [38] developed

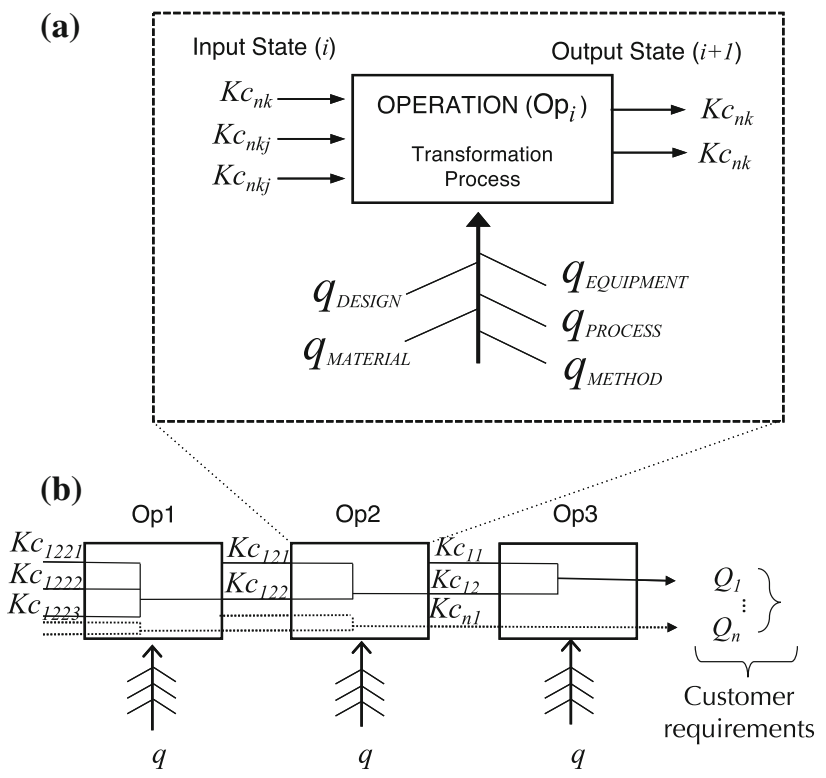

Fig. 1 Model of quality creation during manufacturing a single operation $\mathbf{b}$ entire fabrication process [34]

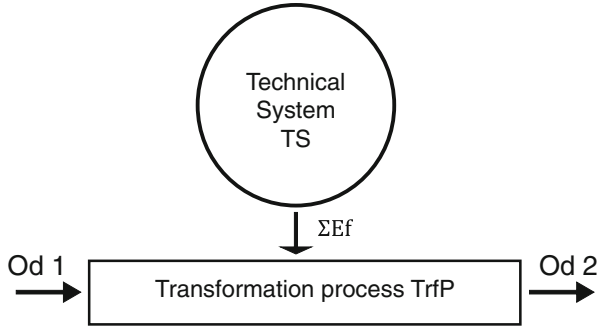

Fig. 2 Transformation process executed by a Technical System as proposed by Hubka and Eder [38]

TTS to support engineering design of technical systems that execute transformation processes to fulfill certain functionalities. In some of their examples, the manufacturing equipment acts as a technical system (TS) that executes the transformation process (TrfP) or physical transformation that occurs to the product during a manufacturing operation. In these cases, the operand (Od) can be considered the workpiece transformed from an input state $\left(\mathrm{Od}_{1}\right)$ to an output state $\left(\mathrm{Od}_{2}\right)$, shown in Fig. 2.

Madrid et al. [34] described this transformation as the propagation of key characteristics (KCs), i.e., product characteristics for which variation is critical to the function and performance quality of the product [35].

In the sequence of manufacturing operations, see Fig. 1b, the KCs act as operands that are being created and transformed until the final operation is reached. By then, the product ought to contain the product characteristics, features, and properties that carry the performance and quality to fulfill the technical needs and requirements of the customer $\left(Q_{i}\right)$. The $Q$-quality concept was adopted from Mørup [40]. The 


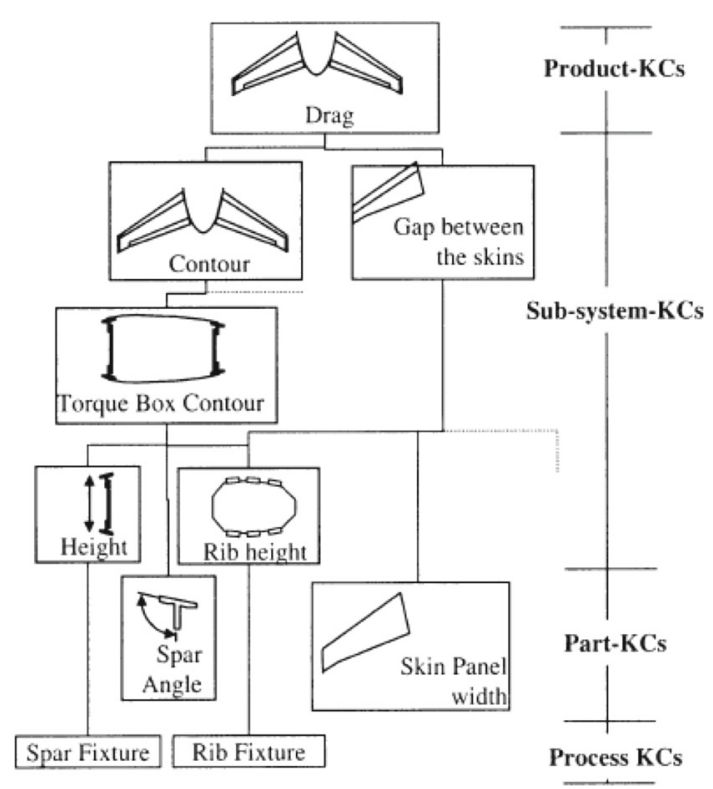

Fig. 3 Example of KC flowdown applied on airplane wings system by Thornton [35]

sequence of KCs is made so that inputs and outputs of each operation (Opi) can represent the variation propagation. In a similar fashion, some authors [41-43] have been using the KC flowdown approach developed by Thornton [35] to determine what drives quality. An example of a $\mathrm{KC}$ flowdown is given in Fig. 3.

In addition, a manufacturing operation can be controlled by factors related to both the product and the manufacturing systems, which in their interactions influence the variation of the operation outcome. To represent these control parameters acting as sources of variation, an Ishikawa diagram developed by Söderberg et al. [39] was adopted. The denotation of control factors is inspired by the concept of q-quality from Mørup [40].

The various sources (denoted as $q_{D E S I G N}, q_{M E T H O D}$, $q_{\text {MATERIAL }}, q_{\text {EQUIPMENT }}, q_{\text {PROCESS }}$ in Fig. 1a) contribute to the variation induced during the transformation of the KCs along a sequence of manufacturing operations.

\section{Welding Capability Assessment Method (WCAM)}

The method proposed in this paper is an extension of previous work that resulted in the model presented in Fig. 1 [34]. This model is aimed at classifying and representing the different factors affecting the product quality creation during the sequence of manufacturing operations. This previous work did not address how to extract and assess those factors.
In this paper, a method is presented that supports the systematic identification and assessment of factors related to the design of the product geometry and that affect the quality of the product resulting from the fabrication process, specifically welding. In this way, the welding capability space is analyzed, thus supporting design space exploration during virtual and interactive design.

In this research, production quality is defined as the concept of capability, as in Quality Engineering theory [44]. Quality is achieved if the output variation of a manufacturing operation is within the tolerance limits. Thus, the manufacturing capability space is defined as the design parameter space that fulfills manufacturing quality.

The Welding Capability Assessment Method (WCAM) entails two mains steps, outlined in Fig. 4.

Step 1 The first step involves identifying the key product characteristics (KCs), output of the welding operation system, critical to ensure product performance quality (big $Q$-quality). The target value and tolerance of each output KC are then set to fulfill technical requirements.

Step 2 The second step involves identifying and assessing the control factors (small q-quality) that influence the welding operation output identified in Step 1, but only those factors related to the product geometry $\left(q_{D E S I G N}\right)$. This step consists of three substeps:

- Step 2.1 The failure modes during welding are identified.

- Step 2.2 The design aspects, $q_{D E S I G N}$, leading to those failure modes are derived.

- Step 2.3 Ways to assess the possible value of those design parameters to avoid welding failure and thus ensuring product quality are proposed. This involves setting tolerances for the design parameters that act as control variables on which the welding output is dependent. In this way, the limits of the welding capability space can be drawn.

This method was developed using data gathered through a combination of interviews, literature of welding handbooks and internal company documents and standards. The contribution to each step of the method from interviews and literature is summarized in Table 1.

Three main groups were targeted as interview subjects: design engineers, welding engineers and welding simulation engineers. The interviews with design engineers were carried out around two topics of discussion. The first part asked about how welds influence product performance. This allowed the identification of generic output KCs, contributing to Step 1. The second part discussed the critical product geometries and design parameters that have conflicting product performance and welding capabilities. The purpose was to seek the design parameters $\left(q_{D E S I G N}\right)$ based on their 


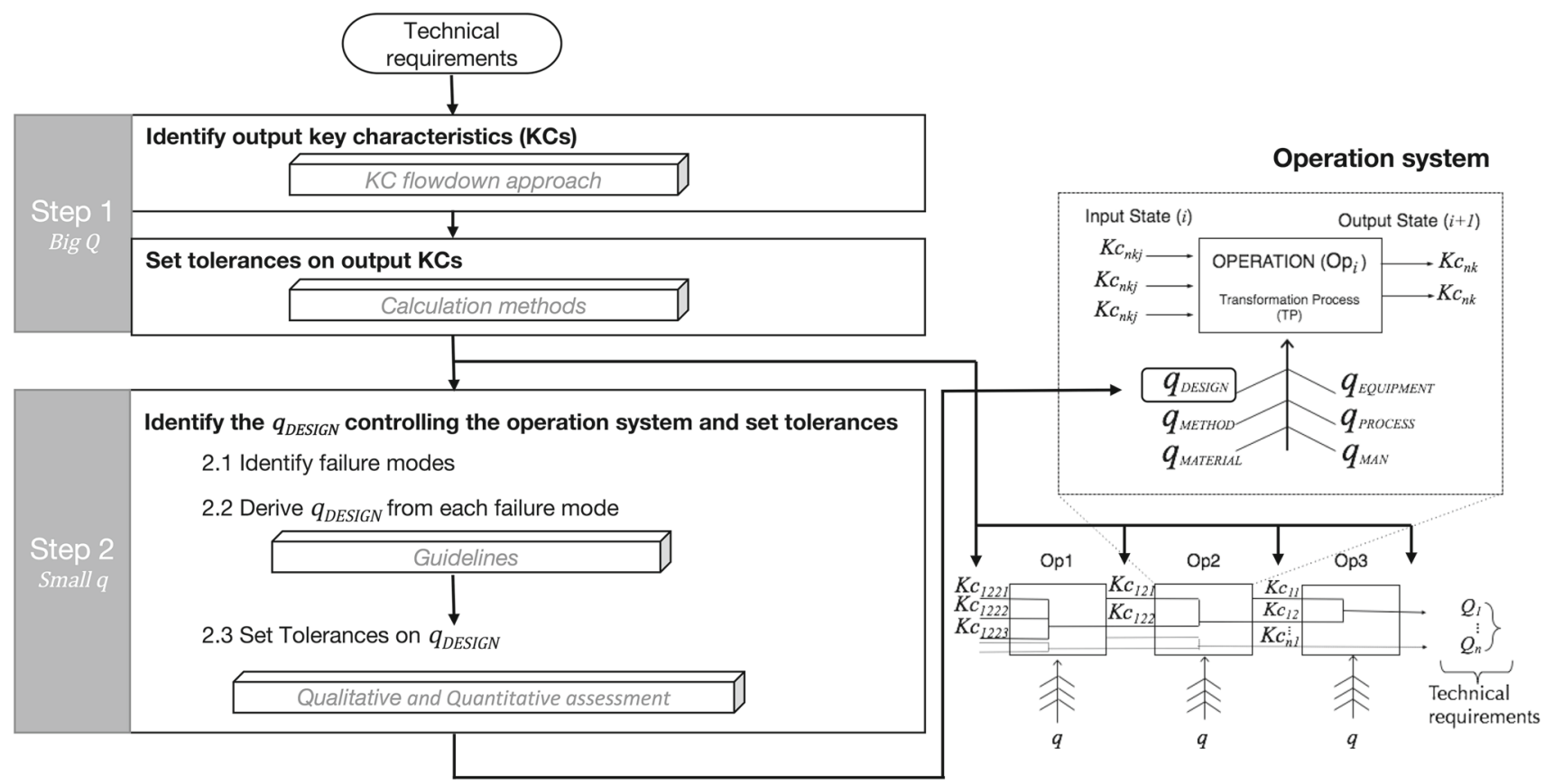

Fig. 4 Welding Capability Assessment Method (WCAM): steps and tools

Table 1 Data collection methods employed in the development of the method steps

\begin{tabular}{llllll}
\hline Respondents & Interview time & Step 1 & Step 2.1 & Step 2.2 & Step 2.3 \\
\hline W.E.1 & $8 \mathrm{~h}$ & & $\mathrm{x}$ & $\mathrm{x}$ & \\
W.E.2 & $8 \mathrm{~h}$ & & $\mathrm{x}$ & $\mathrm{x}$ & \\
W.E.3 & $12 \mathrm{~h}$ & $\mathrm{x}$ & $\mathrm{x}$ & $\mathrm{x}$ \\
W.E.4 & $2 \mathrm{~h}$ & $\mathrm{x}$ & $\mathrm{x}$ & $\mathrm{x}$ \\
W.E.5 & $1 \mathrm{~h}$ & $\mathrm{x}$ & $\mathrm{x}$ & $\mathrm{x}$ \\
W.E.6 & $2 \mathrm{~h}$ & $\mathrm{x}$ & $\mathrm{x}$ & $\mathrm{x}$ \\
W.E.7 & $2 \mathrm{~h}$ & & & & $\mathrm{x}$ \\
W.S.E.1 & $5 \mathrm{~h}$ & & & & $\mathrm{x}$ \\
W.S.E.2 & $4 \mathrm{~h}$ & & & & $\mathrm{x}$ \\
W.S.E.3 & $4 \mathrm{~h}$ & & & & $\mathrm{x}$ \\
D.E.1 & $2 \mathrm{~h}$ & $\mathrm{x}$ & & $\mathrm{x}$ & \\
D.E.2 & $1.5 \mathrm{~h}$ & $\mathrm{x}$ & & & \\
D.E.3 & $1 \mathrm{~h}$ & $\mathrm{x}$ & & $\mathrm{x}$ & \\
D.E.4 & $1 \mathrm{~h}$ & $\mathrm{x}$ & & $\mathrm{x}$ & \\
Literature & {$[4,10,11,29,30$,} & $\mathrm{x}$ & $\mathrm{x}$ & $\mathrm{x}$ & $\mathrm{x}$ \\
& $39,45-50]$ & & & & \\
Company & & $\mathrm{x}$ & $\mathrm{x}$ & $\mathrm{x}$ & $\mathrm{x}$ \\
documents & & & & & \\
\hline
\end{tabular}

W.E. Welding engineer

W.S.E. Welding simulation engineer

D.E. Design engineer

experience in previous programs, thus contributing to Step 2.2.

Half of the interviews were held with welding engineers, during which the aim was to study in detail the phenom- ena occurring during welding operations. These interviews resulted in such outputs as failure modes and connected design parameters $q_{D E S I G N}$ (Steps 2.1 and 2.2). Figure 5 was used as a mediating tool during interviews and a means for coding and categorizing the data. The lists presented in both steps are the result of converging data from these interviews and findings from welding handbooks, in which the areas of interest included weld quality and distortion. The interviews with welding simulation engineers contributed to the development of Step 2.3. Company documents were also used to develop each method step. These documents relate to welding operations, procedure specifications, lessons learned, welding tests, as well as quality requirement standards for aerospace fusion welding.

\subsection{Step 1: identify output KCs and set tolerances}

The first step involves identifying the output required from the welding operation under analysis, i.e. what are the key product characteristics (KCs) transformed and created during the welding operation that are critical to performance quality (big $Q$ ) and setting tolerance limits $(\mathrm{KC}+\mathrm{T})$. A deviation from the target value outside the tolerance limits due to manufacturing variation will affect product functionality (see definition of key characteristics in [35]).

To analyze the robot welding operation system and assess welding capabilities, there is a need to first identify the input and output KCs of the welding system. In this way, the welding operation can be analyzed as a separate system. 


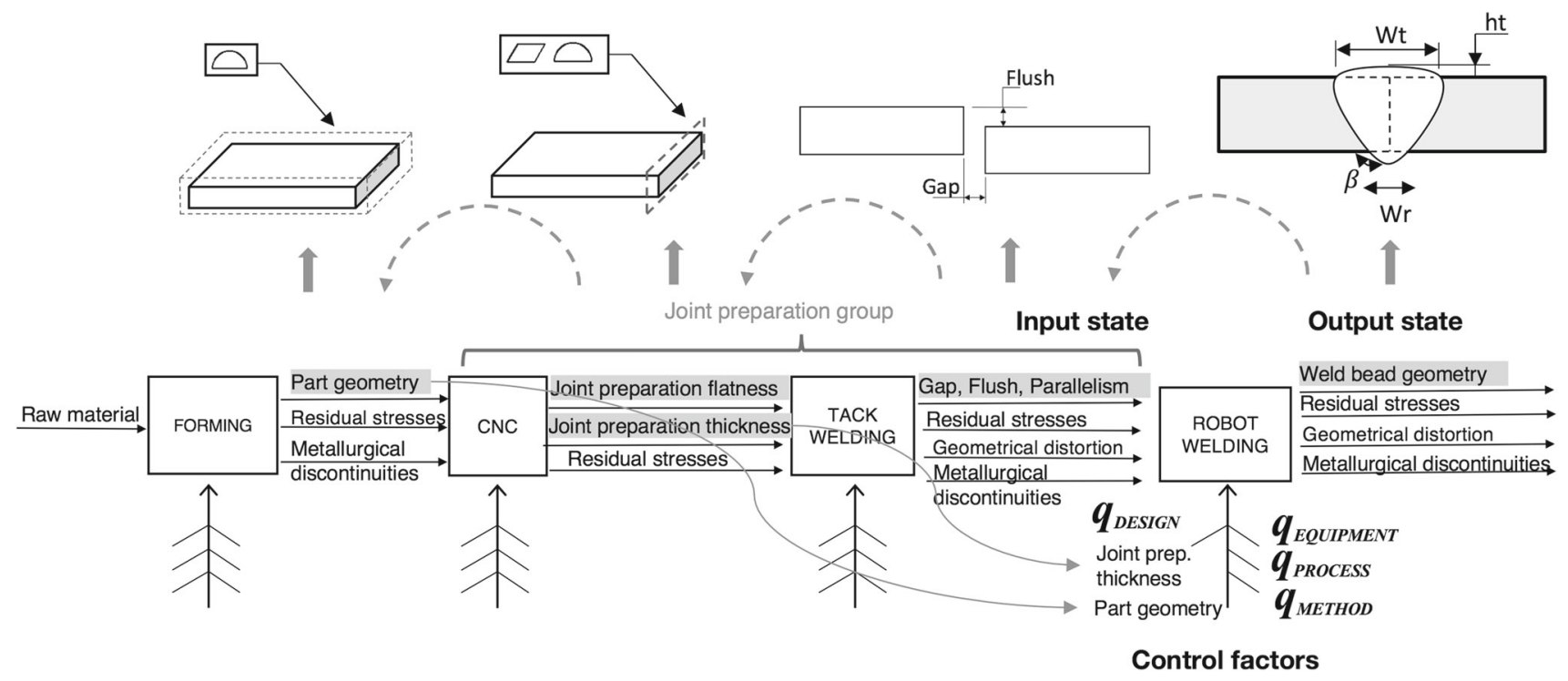

Fig. 5 Quality creation model applied to the fabrication of welded structures

In the identification of input and output KCs, the authors propose using the $\mathrm{KC}$ flowdown approach [35] to study how manufacturing variation in key product characteristics propagates throughout the manufacturing chain. Using the model developed by the authors (see Fig. 1), the KC flowdown can be aligned to the assembly operations that compose the fabrication of aircraft welded structures, in which robot welding is linked to a chain of previous operations. The model applied in an example is presented in Fig. 5.

Therefore, considering the welding operation as a transformation system, the welding outcome depends on the input state, which results from previous operations. For example, the quality of the weld bead geometry is influenced by the output of the tack welding operation, in which proper alignment conditions for the parts to be welded (gap, flush and parallelism) must be guaranteed. During machining operation (Computer Numerical Control CNC), the flatness of the surfaces to be welded and the weld interface profile need to be ensured to deliver proper weld alignment conditions while tacking. Ultimately, the part shape quality given by the net shape forming process will affect the flatness and thickness quality. Studies have also demonstrated that the distribution of residual stresses due to forming or tack welding operations must be considered in the estimation of residual stress due to welding $[30,48]$. In addition, studies have demonstrated that it is important to consider the input part variation, due to the fixturing or forming processes, when simulating the distortion due to welding [46,49].

Furthermore, product characteristics created in previous operations (such as part geometry and joint preparation thickness, as shown in the Fig. 5 example) can act as control factors to the robot welding operation system.
For example, part thickness in combination with the the type of welding method will determine the amount of heat needed, which eventually will influence the distortion. Control factors related to product geometry are identified and assessed in Step 2.

Output KCs For aircraft welded structures, the output key product characteristics $(\mathrm{KCs})$ of a welding operation that will affect product functionality (product life and aerodynamics) include: (1) weld bead geometry, (2) metallurgical weld discontinuities and (3) those dimensions with geometrical variation that due to distortion will affect the performance functions mentioned. In cases where the final assembly has not been reached, geometrical variation after welding can also influence the welding performance of the next subassembly [46].

Target values and tolerances need to be set in the output KCs to fulfill technical requirements. For that purpose, different calculation methods can be used. Table 2 presents an array of tools to set the tolerance limits to ensure the performance of welded aircraft structures.

(1) KCs: weld bead geometry The weld bead geometry is described by certain parameters or $\mathrm{KCs}(\mathrm{Wt}, \mathrm{Wr}, \beta$, ht) that define weld bead quality (see Fig. 5). Calculation methods for aerodynamics and fatigue life analysis, such as those listed in Table 2, are used to define the dimensions of the weld bead geometry (see Fig. 5). The dimensions of the weld bead can affect aerodynamics and product life. For example, the weld bead high (KC: ht) can work as a step in the air flow if the weld is located perpendicularly to the flow path. A small weld bead angle (KC: $\beta$ ) acts as a sharp edge, concentrating a lot of tension which affects the mechanical properties. 
Table 2 Calculation methods to set tolerance limits in output KCs

\begin{tabular}{|c|c|c|c|}
\hline Identified output $\mathrm{KC}$ & Connection to performance (big Q-Quality) & Calculation methods for setting tolerances & Limits \\
\hline \multirow[t]{2}{*}{ (1) Weld bead geometry } & Fatigue life & Crack propagation calculation method (ex. Paris' law) & $\mathrm{KC} 1+\mathrm{T}$ \\
\hline & Aerodynamics & Computational Fluid Dynamics (CFD) & $\mathrm{KC} 2+\mathrm{T}$ \\
\hline (2) Metallurgical discontinuities & Fatigue life & Crack propagation calculation method (ex. Paris' law) & $\mathrm{KC} 3+\mathrm{T}$ \\
\hline \multirow[t]{3}{*}{ (3) Form dimensions } & Fatigue life & Structural finite element analysis & $\mathrm{KC} 4+\mathrm{T}$ \\
\hline & Aerodynamics & Computational Fluid Dynamics (CFD) & $\mathrm{KC} 5+\mathrm{T}$ \\
\hline & Performance of the next assembly & Variation simulation & $\mathrm{KC} 6+\mathrm{T}$ \\
\hline
\end{tabular}

Severe changes in geometry lead to strong notch effects and associated stress concentrations [29]. Thus, a definition of weld bead geometry and its tolerances is required [47].

(2) KCs: Metallurgical discontinuities Metallurgical weld discontinuities, such as cracks and pores, are a natural effect of the welding process. These discontinuities reduce the cross-sectional area, thus amplifying stresses [29]. The limits of these defects regarding number, size and location, are determined by crack propagation calculation methods.

(3) KCs: Form dimensions of the edges Geometrical variation in form dimensions of the final product due to product distortion change the stress distribution, affecting the fatigue life of the product as well as the aerodynamics, as studied by Forslund [4]. Therefore, form tolerances on the output dimensions of this sub-assembly are needed. In addition, due to the variation stack up, in order to ensure alignment conditions (gap, flush, parallelism) for the performance of the next welding operation, the edges that will conform to the joint in the next assembly require special form tolerances. Variation simulations are used to estimate the output result and set tolerances $[39,46]$.

\subsection{Step 2: identify $q_{D E S I G N}$ and define their tolerances}

In the second step, the objective is to identify and assess the product design aspects that cause manufacturing variation in output KCs of the welding system, which were identified in Step 1.

Considering all of the potential factors that can cause manufacturing variation, the objective is to identify those factors related to the design, defined by the authors as $q_{D E S I G N}$ (see Fig. 4).

A number of substeps proceed to complete this second stage:

- Step 2.1 Failure modes during welding are identified.

- Step 2.2 Control key product characteristics $\left(q_{D E S I G N}\right)$ causing the failure modes are identified.
- Step 2.3 The design space from the perspective of welding capabilities is assessed and tolerance limits are set to the key control product characteristics $\left(q_{D E S I G N}\right)$ that act as control parameters to the welding operation system.

Table 3 presents the three substeps of Step 2. The first and second columns connect each possible failure mode of the welding transformation system to the geometrical design cause $\left(q_{D E S I G N}\right)$. The list of failure modes and design parameters $\left(q_{D E S I G N}\right)$ are presented and elaborated on below. Note that in some cases, a specific geometrical characteristic can lead to different failure modes. The right side of the table presents different possible means of assessment (qualitative and quantitative).

\subsubsection{Step 2.1: Identify failure modes of the process}

The failure modes, as defined by the authors, are the different manners in which the welding process can fail. A failure can occur either when the welding output exceeds tolerance limits, or when the operation cannot be performed due to, for example, accessibility problems.

Nine common welding failure modes have been identified and presented as guidelines. In this study, only failure modes relevant to aerospace applications have been considered.

The following list of failure modes has been synthesized from the interviews and documents listed in Table 1:

Failure mode 1: Incomplete joint penetration (also defined as lack of penetration) This failure mode is related to the weld bead geometry. As described in [30,45], an incomplete joint penetration occurs when the intended weld depth has not been reached, thus showing a visible gap on the root side of the weld (see Fig. 6). Among other types of discontinuities related to the weld bead geometry such as undercut or underfill, incomplete joint penetration can be considered one of the most severe due to its repair cost. To repair this discontinuity, the weldment must be cut up and a completely new weld needs to be performed. 


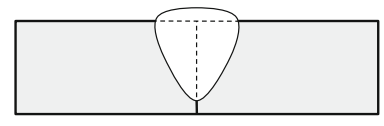

Incomplete joint penetration

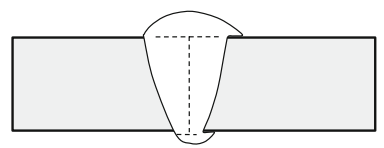

Overlap

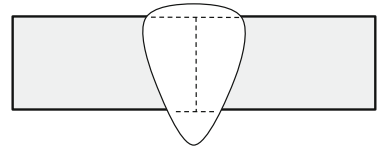

Excessive root reinforcement (overfill)

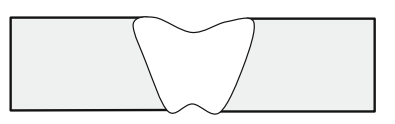

Underfill in both top and root side
Fig. 6 The four failure modes related to weld bead geometry

Failure modes 2 and 3: Underfill and excessive root reinforcement Underfill occurs when the surface of the top side of the weld is below the adjacent surface of the base material (see Fig. 6). Normally, this discontinuity is corrected by adding one or more additional layers of weld metal to the joint (multiple weld passes), which can cause more distortion as explained below (see Failure mode 6). Underfill can also be seen as a consequence of excessive root reinforcement. The vertical dropping of the fused metal can cause an overfill on the root side, thereby causing an underfill on the topside due to vertical displacement of the fused material, pushed by the gravity forced. Figure 6 illustrates this phenomenon.

Failure mode 4: Overlap Overlap can happen when the fluid weld metal flows to the base material without any resulting fusion. Fused metal lies over unfused metal forming a severe mechanical notch, as shown in Fig. 6.

The four failures modes described in Fig. 6 related to weld bead geometry compromise the product life of the component as it increases the probability of fracture as explained in Step 1 (see Sect. 3.1).

Failure mode 5: Distortion (primary) During welding, the heating and cooling cycle makes the weld metal and adjacent base metal expand and contract. This phenomenon creates stresses and shrinkage forces that lead to product distortion. Three fundamental dimensional changes can cause transverse, longitudinal and angular distortions. When these dimensional distortions occur simultaneously, they can induce buckling. Product distortion translates into deformation at the edges, causing misalignments in the next assembly level. Distortion is a consequence of material shrinkage if the part is not being restrained. However, conditions of high restraint increase the likelihood that hot or cold cracks may initiate in the weld metal or heat-affected zone [29].

Failure mode 6: Distortion (due to multiple weld passes) Welding is ideally performed in one weld pass. However, when welding is performed in multiple passes, particularly when the expected weld bead geometry cannot be initially achieved, shrinkage is accumulated. The more the shrinkage accumulates, the greater the distortion. Therefore, the distortion from multiple weld passes is defined as a failure mode and separate from primary distortion, because primary distortion, as here defined, can only be mitigated but not avoided.

Failure mode 7: Metallurgical discontinuities Pores and cracks are examples of metallurgical discontinuities, which represent changes in the properties of the weld or base metals. Depending on the shape, size, quantity, distribution and orientation of the discontinuities within the weld, the effect on mechanical properties can be more or less severe.

Failure mode 8: Limited access to weld Accessibility is a failure mode, as it inhibits the welding operation from being executed. Limited access to welding makes it difficult for the welder to precisely guide the welding process and increases the likelihood of other failure modes, such as metallurgical discontinuities or weld bead geometry discontinuities [29].

Failure mode 9: Limited access to inspect In aerospace applications, the inspection requirements demand every weld to be inspected. Accessibility to inspect is as important as accessibility to weld.

\subsubsection{Step 2.2: Derive $q_{D E S I G N}$ from each failure mode}

In this step, the authors intend to establish a link between control product characteristics $\left(q_{D E S I G N}\right)$ and the failure modes previously presented. This link is provided in Table 3.

Each failure mode is modelled by considering the underlying physics of the transformation process that occurs during the welding operation. During a welding operation, many phenomena occur involving specific part geometry and welding parameters. Currently, there does not exist a precise process model or simulation tool that can accurately predict the likely success of the process. In some cases approximate models exist, but in other cases such models may need to be developed from scratch. Therefore, at this stage, if quantitative models of the physical phenomenon are not possible, experts working with the welding process can make qualitative descriptions of the phenomena occurring and qualitative evaluations of the design aspects that intervene in the phenomena.

Therefore, the objective of this step is to derive the control product characteristics $\left(q_{D E S I G N}\right)$ from the descriptions of the physical failures. From each failure mode, a $q_{D E S I G N}$ can be derived, acting as a metric of the welding success or failure. A list of different $q_{D E S I G N}$ that need to be considered during the design process and how they lead to different welding failure modes is presented as a guideline. This list of design 
Table 3 Step 2 in Welding Capability Assessment Method

\begin{tabular}{|c|c|c|c|c|c|}
\hline Step 2.1 & Step 2.2 & \multicolumn{4}{|c|}{ Step 2.3} \\
\hline \multirow[t]{2}{*}{ Failure mode } & \multirow[t]{2}{*}{$q_{D E S I G N}$} & $\begin{array}{l}\text { Qualitative } \\
\text { assessment }\end{array}$ & \multicolumn{3}{|c|}{ Quantitative assessment } \\
\hline & & $\begin{array}{l}\text { (Higher probability } \\
\left.\text { of failure if } q_{D E S I G N}\right)\end{array}$ & $\begin{array}{c}\text { Standards } \\
\text { Handbooks }\end{array}$ & $\begin{array}{l}\text { Physical } \\
\text { test }\end{array}$ & $\begin{array}{c}\text { Simulation } \\
\text { test }\end{array}$ \\
\hline Incomplete joint penetration & Thickness (t) & Increases & Yes & Yes & No \\
\hline $\begin{array}{l}\text { Incomplete joint penetration } \\
\text { Underfill \& excessive reinforce- } \\
\text { ment root side }\end{array}$ & $\begin{array}{l}\text { Thickness } \\
\text { uniformity }\left(u_{t}\right)\end{array}$ & Increases & No & Yes** & No \\
\hline $\begin{array}{l}\text { Overlap root side } \\
\text { Limited accessibility to inspect }\end{array}$ & Inner radius $(r)$ & Decreases & No & Yes** & $\begin{array}{l}\text { CAD model } \\
\text { offset } \\
\begin{array}{c}\text { Path planning } \\
\text { simulation }\end{array}\end{array}$ \\
\hline $\begin{array}{l}\begin{array}{l}\text { Limited accessibility to weld } \\
\text { (limited robot rotation) }\end{array} \\
\text { Incomplete joint penetration } \\
\text { Overlap top side } \\
\begin{array}{l}\text { Distortion (Multiple weld } \\
\text { passes) }\end{array}\end{array}$ & Outer radius (R) & Decreases & No & Yes** & $\begin{array}{c}\begin{array}{c}\text { Path planning } \\
\text { simulation }\end{array} \\
\begin{array}{c}\text { Authors } \\
\text { proposition * }\end{array} \\
\begin{array}{c}\text { Welding } \\
\text { simulation }\end{array}\end{array}$ \\
\hline Limited accessibility to inspect & Width (w) & Decreases & No & Yes & $\begin{array}{l}\text { Path planning } \\
\text { simulation }\end{array}$ \\
\hline Limited accessibility to weld & \multirow{2}{*}{ Distance $(H)$} & \multirow[t]{2}{*}{ Decreases } & \multirow[t]{2}{*}{ No } & \multirow[t]{2}{*}{ Yes } & $\begin{array}{l}\text { Path planning } \\
\text { simulation }\end{array}$ \\
\hline $\begin{array}{l}\text { Weld bead geometry issues and } \\
\text { metallurgical discontinuities }\end{array}$ & & & & & No \\
\hline Distortion & $\begin{array}{l}\text { Distance }(H) \\
\text { Length }(l) \\
\text { Inclination }(\theta)\end{array}$ & Increases & No & Yes** & $\begin{array}{l}\text { Welding } \\
\text { simulation }\end{array}$ \\
\hline
\end{tabular}

* See Case study Section

** Expensive test if many product geometry variants need to be tested

parameters $q_{D E S I G N}$ has been created from the information collected through interviews and documents as explained in Table 1:

Joint thickness ( $t$ ) The thickness of the joint will determine whether it is possible to achieve complete joint penetration in a single weld pass for the material and welding method chosen. Joint penetration is related to the heat transfer phenomena that occur within the welded material. Depending on the material and welding method, the heat will be able to reach a certain depth. Each material has its own thermal conductivity and each welding method transfers the heat into the material differently. In addition, the plate thickness has a strong effect on the heat flow. A transition from 2D to 3D heat flow can occur, hampering the complete joint penetration.

Thickness uniformity error $\left(u_{t}=t_{\max }-t_{\min }\right)$ Due to functional purposes, a product can be designed with different thickness along the joint (sometimes referred to as taper zones). A significant change in thickness within a short distance will not allow the welding method to rapidly adjust the welding parameters, thus resulting in discontinuities. The thicker area $\left(t_{\max }\right)$ would result in incomplete joint penetration whereas the thinner area $\left(t_{\min }\right)$ would have excessive reinforcement on the root side coupled with underfill on the top side.

Inner radius $(r)$ In the case of a curved weld, the inner radius of the curve can cause overlap on the root side as shown in Fig. 7. This is related to the depth of the weld bead root side. The weld root of the two welded sides converging on the corner can overlap causing a notch area similar to a crack. Since access inside the curved area needs to be provided to ensure visibility according to the requirements of the NonDestructive Testing (NDT) methods chosen, the inner radius can also limit the inspectability of the root side of the weld. 

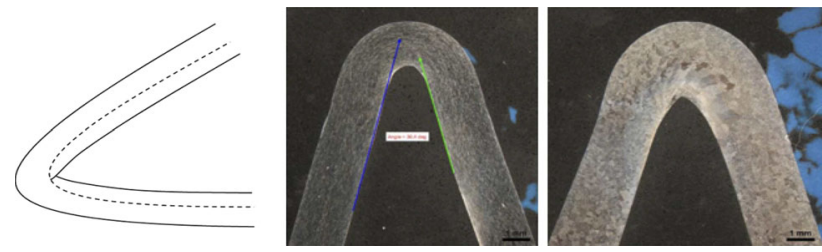

Fig. 7 a Overlap illustration; b weld root before welding; c weld root after welding showing overlap

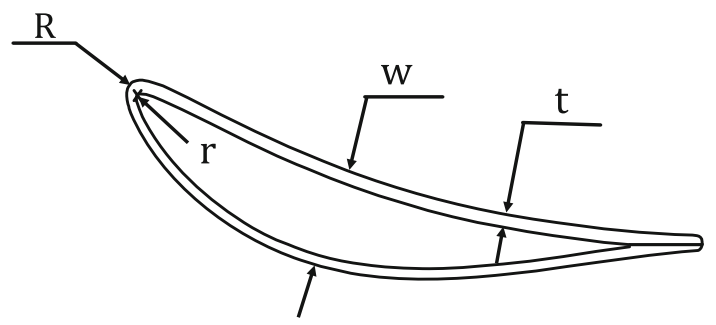

Fig. 8 Common example of a parameterized cross-section of a closed weld in an aircraft blade application

Outer radius $(R)$ In the curved region of a closed weld, the robot and the part to be welded need to synchronize their movements so that the robot adopts a normal position to the part at any instant. Therefore, the outer radius of the curve, $\mathrm{R}$, can limit the relative movement between the part and robot, thereby obstructing the operation. Having overcome this operational failure, there are other failures particularly of closed joints and related to weld quality. When welding the curved area, the welding torch turns around the part rotating around the same point for several instances, which causes increases in the volume of the melted pool and temperature in the material, thereby increasing viscosity. If the volume of the melted pool is bigger and the viscosity higher, the effect of gravity, when part and robot are moving, will cause a higher drop of melted material which can lead to overlap discontinuities on the top side and incomplete joint penetration on the root side. Reducing the power effect in the curve through the welding parameter settings may be an option to address this failure. However, a drastic drop of the power effect can cause incomplete joint penetration problems. Thus, an approach that sometimes is adopted to ensure weld bead quality is to employ multiple weld passes around the curved area, which consequently will lead to more distortion.

Width of the curved weld ( $w$ ) As seen in Fig. 8, the width of the curved weld can also limit the inspectability on the root side of the weld.

Position of the weld (parameters defining the position of the weld, distance $H$, inclination $\theta$, length $l$ ) The design of form division, meaning where to locate the split lines, can be related to several failure modes, both operation failures related to accessibility and inspectability, but also quality

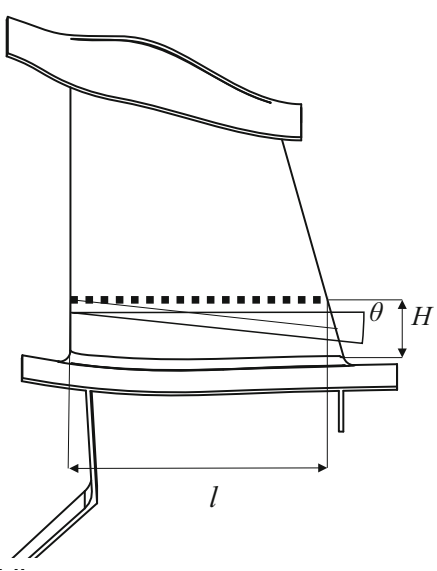

Fig. 9 Common example of a parameterized cross-section of a closed weld in an aircraft blade application

failures connected to distortion and weld bead geometry. To facilitate the analysis, the position of the weld can be parameterized. An example of a common weld in aerospace application, which has been parameterized, is shown in Fig. 9.

Distance $(H)$ The parameter $H$ defines the distance between the weld and a nearby product element. This distance can limit the accessibility of both the welding torch and the equipment to inspect. The preferable position of the welding torch towards the weld joint is $90^{\circ}$. A deviation from that normal direction can have an effect on the weld bead geometry or metallurgical discontinuities, thus affecting weld quality [50].

In addition, the position of the weld $(H, \theta, l)$ (see Fig. 9) will determine the respective volume of mass on each side of the weld joint which can influence the distortion during welding due to product asymmetry. One of the basic recommendations adopted by qualitative DFM guidelines about welding is that distortion can be reduced by designing symmetry in parts [10].

\subsubsection{Step 2.3: Set tolerances on $q_{D E S I G N}$}

Once each $q_{D E S I G N}$ has been derived from each failure mode, the next step is to identify the range of action for each. That means setting tolerances on $q_{D E S I G N}$ that represent how much the value of $q_{D E S I G N}$ can vary while still guaranteeing a successful operation. This defines the welding capability space for each control product characteristic $\left(q_{D E S I G N}\right)$.

Both qualitative and quantitative sources of data can be used to analyze the $q_{D E S I G N}$ tolerance values. Expert knowledge of process capability, historical manufacturing data, laboratory and simulation data can be employed to make both qualitative and quantitative assessments. 
In Step 2.3 within Table 3, under qualitative assessment, relations between failure modes and $q_{D E S I G N}$ have been studied through qualitative data from interviews in Table 1. For each $q_{D E S I G N}$ extracted in previous steps, the table indicates a higher probability of failure if the nominal value of $q_{D E S I G N}$ increases or decreases. This qualitative assessment serves as an initial guide to quickly evaluate the impact of the design on welding outcomes. However, this needs to be complemented with quantitative assessments to provide a more accurate evaluation that can support tolerancing. Thus, on the right side of Table 3, methods for quantitative assessment have been identified, presenting a gap and opportunity analysis. Some of the failure modes and related $q_{D E S I G N}$ demonstrate a lack of quantitative assessment tools.

First, a description of the qualitative relations presented in Table 3 is presented for each $q_{D E S I G N}$. Thereafter, quantitative methods are discussed.

\section{Qualitative assessment (see Table 3):}

Thickness ( $t$ ): The thickness of the joint is one of the main variables to determine the choice of welding method. Each welding method has a range of joint thicknesses for which the method is capable of achieving complete joint penetration. Outside this joint thickness range, no combinations of welding parameters would be able to achieve complete joint penetration in a single weld pass. Within the capability limits, thicker materials (in Table 3: $t$ increases) cause greater difficulty in achieving complete joint penetration due to the 3D heat flow behaviour; i.e., there is a larger volume of surrounding material that dissipates the heat, hindering the heat from flowing to the root of the joint.

Thickness Uniformity Error $\left(u_{t}\right)$ : If thickness uniformity error $\left(\mathrm{u}_{\mathrm{t}}=\mathrm{t}_{\max }-\mathrm{t}_{\min }\right)$ increases, the difference in thickness between the thicker and thinner sections becomes greater which increases the probability of failure. For a constant set of welding parameters, the thicker area exhibits greater probability of incomplete joint penetration whereas the thinner area exhibits greater probability of underfill and excessive root reinforcement.

Inner radius $(r)$ : With regard to weld bead geometry failures, as explained in Step 2.2, the inner radius can cause overlap on the root side. The smaller the radius, the higher the probability of overlap on the root side (see Fig. 7). The accessibility to inspect can also be limited by this parameter. Narrower inner radii are more difficult to inspect inside the root side of the weld.

Outer radius $(R)$ : Narrower outer radii are more difficult to rotate around the curve while welding. A sharp outer radius would place high demands on synchronizing the robotworkpiece movement. Additionally, this relative movement between robot and workpiece to constantly try to obtain a per- pendicular position of the weld torch towards the joint can cause failure including overlap and incomplete joint penetration. A narrower outer radius makes the torch rotate longer around the same centre point, thereby overheating the curved area and causing a larger weld pool (melted material) with higher viscosity due to the increment in temperature. Therefore, if the radius decreases, the probability of dropping the weld pool causing a top side overlap increases. A first option to deal with a narrow radius would be to reduce the power effect in the curved area, which may cause complete joint penetration. Another option would be to undertake a second weld pass, which would cause greater distortion but ensure weld bead quality.

Width of the curved weld (w): Narrower welds (in Table 3: w decreases) offer more limited accessibility to inside inspections.

Position of the weld $(H, l, \theta)$ : The form division design, or where to locate the split lines (welds), affect accessibility. If $H$ decreases so that the weld is located closer to the nearby object, the access of the welding torch becomes more limited. Also, if $H$ decreases so that the torch does not achieve a preferable $90^{\circ}$ position towards the joint, the probability of metallurgical discontinuities and weld bead geometry related failures becomes higher.

In the last row of Table 3, the failure mode distortion is related to the design parameters that define the position of the weld $(H, l, \theta)$. An increase in asymmetry and twist (mainly defined by $\theta$ ), would increase the probability of distortion.

\section{Quantitative assessment (see Table 3):}

Welding handbooks Thickness ranges for different materials and welding methods have been extensively studied and can be found in welding handbooks $[30,45]$. Some recommendations about thickness uniformity and relations between the thinner and thicker parts of a joint can be found in guidelines and company standards, however not for all combinations of welding methods and materials. Still, physical experimentation is required. Recommendations regarding remaining design parameters considered under Table 3 are vague or non-existent.

Physical tests Quantitative assessments that would indicate a range of action for parameters $r, R$ and $H$ with regard to weld quality problems are difficult to perform and may only be performed via physical tests. Today, in industry practice, welding simulations cannot reproduce solidification phenomena when forming the weld bead nor the creation of material microstructure and metallurgical discontinuities. Therefore, design parameter ranges become known because of physical experimentation. However, physical tests are expensive to perform when the effect of different geome- 


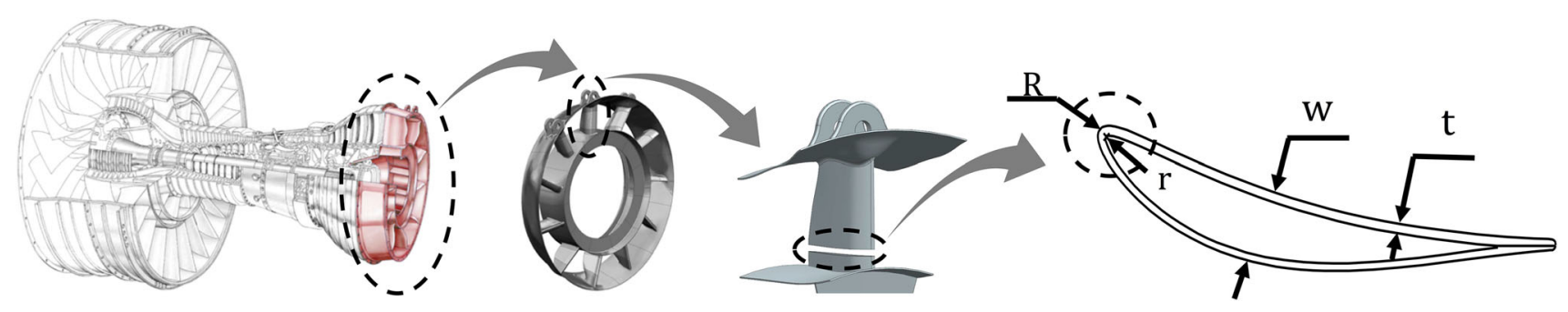

Fig. 10 Decomposition from product system to component level to part level to weld interface. Problematic area is indicated in weld cross-section

tries is being analyzed. With regard to accessibility, physical tests can be used to study the interaction between the welding and inspection equipment towards the part. Nevertheless, simulation is more advanced in this area.

Simulation tests In industrial practice, welding simulations (sometimes combined with variation simulations) are extensively employed to calculate distortion, i.e. to study macro-level product deformation, and residual stresses [46]. However, not all phenomena related to welding can be virtually modelled. In today's industry, simulations are not available to predict weld quality from material microstructure, metallurgical discontinuities and weld bead geometry. Nevertheless, in this paper, the authors propose a method using welding simulations to study incomplete joint penetration and overlap (see Case Study section). With regard to accessibility, mathematical models can be developed connecting the welding torch and product model dimensions (including split lines) [51]. There also exists path planning software to study the collisions and movements of the robot in relation to the range of values for different geometrical parameters [52].

\section{Case Study: GTAW welding}

Through a case study, the method proposed is justified and applied to a concrete weld within an aircraft engine structure. The approach can help designers identify critical design characteristics to the welding operation and the means for assessing the design space regarding welding capabilities.

The product selected is a component of a turbofan engine, the so-called Turbine Exhaust Case (TEC) (see Fig. 10). The TEC is a product situated at the rear frame of a jet engine, in the path of exhaust gases, where it is exposed to temperatures up to $700 \mathrm{C}$ during normal flight conditions. The TEC also works as a mounting device to secure that the engine is attached to the wing of the aircraft, as well as serving as a load carrier for other systems. Therefore, this structure must withstand significant thermal and structural loads. In addition, the component needs to be as light as possible and possess good aerodynamic properties to optimize fuel efficiency and reduce $\mathrm{CO} 2$ emissions.
For today's larger engines, the turbine structures are welded assemblies. Materials employed in their fabrication are nickel-based super alloys due to their high temperature resistant properties. Different welding methods are also employed for their fabrication. This component is common in various product families and four variants belonging to such product families have been studied. The differences among the variants concern such features as the size or product structure or the number of blades. However, all variants share similar weld features. They all include a split line in the blade (a closed weld that connects the blade to the rest of the structure as shown in Fig. 10). This type of weld is characterized by a complex contour geometry (see weld cross-section in Fig. 10). Among the various potential welding methods to employ, gas tungsten arc welding (GTAW) has been selected for the case study. GTAW welding, commonly known as tungsten inert gas (TIG) welding, is an arc welding process that employs a non-consumable tungsten electrode to create the weld.

Several factors make the welding of this contour more troublesome than, for example, a straight weld of two identical thick plates, a common example used in welding research. From production experience, it has been concluded that some of the problems aggregate in the curved area of the weld where many phenomena occur during welding (see problematic area indicated by a slashed circle in Fig. 10). A repeated problem identified among many product variants sharing the same type of weld contour is related to weld bead quality and will be the focus of this case study.

Therefore, in this case study, the GTAW welding operation is the system under evaluation. The aim is to assess the control factors related to product design $\left(q_{D E S I G N}\right.$, as defined by the authors) affecting the weld bead quality, the output of the welding operation (see Fig. 11).

\subsection{Step 1: Identify output KCs and set tolerances}

The first step is to identify the required output of the welding operation to ensure product performance quality. This involves setting requirements and tolerances in the weld bead geometry to ensure product functionality. 
Input state
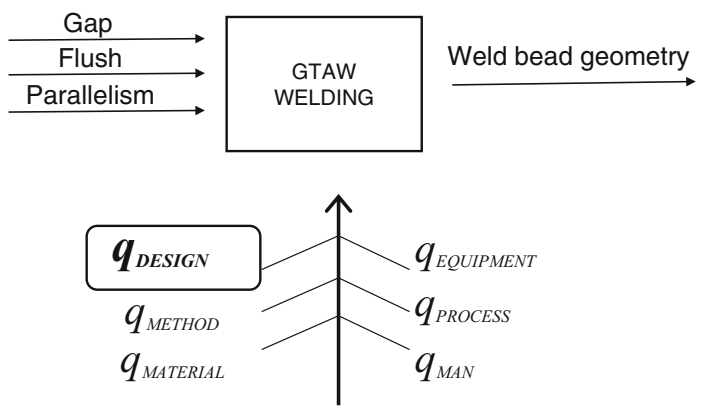

Control factors

Fig. 11 GTAW welding operation system representation using the model developed by the authors

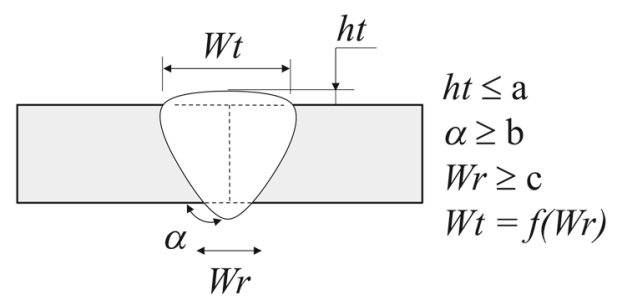

Fig. 12 Parameterized weld bead. KCs and their tolerances

Different requirements will be set according to the service needs of the weld after which welds are categorized in different classes. Every weld is exposed to different stresses depending on where in the product the weld is located and the external loads in that area. A weld located in a high stress region will place higher demands and thus more stringent requirements on its weld bead geometry than a weld located in a low stress area. Thus, a weld class is determined by the geometry of the product and external loads. Standards are established for the different weld classes defining the required dimensions and tolerances of the weld bead [52].

In this case, the weld under study is classified as class A (highest requirements). The weld bead geometry has been parameterized. Each parameter $\left(W_{t}, W_{r}, h_{t}\right.$ and $\left.\alpha\right)$ represents output KCs of the welding operation.

Tolerances on $W_{t}, W_{r}, h_{t}$ and $\alpha$ are set as indicated in Fig. 12 to ensure that the product will not fracture due to mechanical or thermal loads. Tolerance on $h_{t}$ are set so that the height of the weld bead does not inhibit the airflow, thereby harming the aerodynamic performance.

\subsection{Step 2: Identify $q_{D E S I G N}$ and define their tolerances}

The second step is to identify and assess the control product characteristics that influence the output of the welding, KCs identified in Step 1, but only those control product characteristics related to product shape/ geometry $\left(q_{D E S I G N}\right)$. This step consists of three subsequent steps where the failure modes during welding are identified in Step 2.1; the design aspects $\left(q_{D E S I G N}\right)$ leading to those failure modes are extracted in Step 2.2 ; and finally, the values of the design parameters ( $\left.q_{D E S I G N}\right)$ to avoid welding failure, thus ensuring product quality, are assessed in Step 2.3.

\subsubsection{Step 2.1: Identify failure modes of the process}

In this particular case, the failure modes identified at the curved area of the weld are:

- Failure mode 1: incomplete joint penetration

- Failure mode 2: overlap

Both failure modes relate to weld bead geometry and could be described as follows: when workpiece and welding torch are turning relatively around the curved area to ensure normal position at every instance, the melted material, due to the gravity effect of the turn, drops causing overlap on the top side. In addition, in the curved area because the same points are being overheated several instances due to the turn, the heat effect is higher than in the straight area. More heat implies a larger weld pool (melted material) size and higher viscosity, which aggravates the dropping effect, causing more overlap on the top side and incomplete joint penetration on the root side.

\subsubsection{Step 2.2: Derive $q_{D E S I G N}$ from each failure mode}

From the guidelines presented in Section 3, the design parameters $\left(q_{D E S I G N}\right)$ that can lead to failure modes previously described include:

- Radius $(R)$

- Joint thickness $(t)$

- Thickness uniformity $\left(u_{t}\right)$

General descriptions of the physical phenomena involving these design parameters $\left(R, t, u_{t}\right)$ potentially leading to the failure modes understudy can be found in the method section (Table 4 shows a fragment of Table 3 presented in the method section).

\subsubsection{Step 2.3: Set the tolerance on $q_{D E S I G N}$}

The final objective of the case study is to explore and assess the capability space of the GTAW welding method when welding nickel-base super alloys in curved joints. Therefore, this final step involves finding the values that the geometrical parameters identified $\left(q_{D E S I G N}\right)$ can adopt to ensure no overlap on the top side and complete joint penetration. 
Table 4 Fragment of Table 3

\begin{tabular}{|c|c|c|c|c|c|}
\hline Step 2.1 & Step 2.2 & Step 2.3 & & & \\
\hline \multirow[t]{2}{*}{ Failure mode } & \multirow[t]{2}{*}{ qDESIGN } & \multirow{2}{*}{$\begin{array}{l}\text { Qualitative assessment } \\
\text { (Higher probability of failure if } q_{D E S I G N} \text { ) }\end{array}$} & \multicolumn{3}{|l|}{ Quantitative assessment } \\
\hline & & & Standards Handbooks & Physical test & Simulation test \\
\hline $\begin{array}{l}\text { Incomplete joint } \\
\text { penetration }\end{array}$ & $t$ & Increases & Yes & Yes & No \\
\hline $\begin{array}{l}\text { Incomplete joint } \\
\text { penetration }\end{array}$ & $u_{t}$ & Increases & No & Yes** & No \\
\hline \multicolumn{6}{|l|}{$\begin{array}{l}\text { Underfill \& excessive } \\
\text { reinforcement root side }\end{array}$} \\
\hline $\begin{array}{l}\text { Incomplete joint } \\
\text { penetration }\end{array}$ & $R$ & Decreases & No & Yes** & Authors proposition* \\
\hline Overlap top side & & & & & \\
\hline
\end{tabular}

Methods available to study this relationship quantitatively can be carried out only when data are generated through physical tests. However, this option becomes infeasible due to the high cost of the experiments when a large number of design variants need to be tested.

For this reason, the authors propose the use of welding simulations as aids to perform these tests and assess welding capabilities. Simulation results will then be combined with qualitative data from expert interviews.

In this case study, the authors assume total joint thickness uniformity, which indicates that there are no taper zones $\left(u_{t}=0\right)$. Therefore, the capability study focuses on the design parameters radius $(R)$ and joint thickness $(t)$. The nonexistence of taper zones makes the relationship between inner radius and outer radius $R=r+t$.

The design space of the study is composed of five varying joint thicknesses $[1.5 ; 2 ; 2.5 ; 3 ; 3.5 \mathrm{~mm}]$ and five different radii $[1.5 ; 2 ; 2.5 ; 3 ; 3.5 \mathrm{~mm}]$. All variants have constant thickness along the weld, leading to a total of 25 product variants that are to be tested.

Quantitative assessment method Welding simulations are commonly used to study the geometrical deformation on a macro level (distortion) and residual stresses. However, the weld bead quality, including weld bead geometrical discontinuities, cannot be virtually predicted. In welding simulations, internal stress, strain and temperature are calculated for each element. The authors propose to study the relationship of geometrical parameters ( $R$ and $t$ ) and failure modes in the curved area, related to weld bead quality, (overlap and incomplete joint penetration) by checking the nodal temperature.

The effect of thickness and radius is studied by comparing the temperatures of equivalent nodes (located at the same distance from the weld interface) in the straight and curved area of the weld, respectively (see Eq. (1)).

Temperature ratio $=\frac{T_{\text {curved }}\left({ }^{\circ} \mathrm{C}\right)}{T_{\text {straight }}\left({ }^{\circ} \mathrm{C}\right)}$

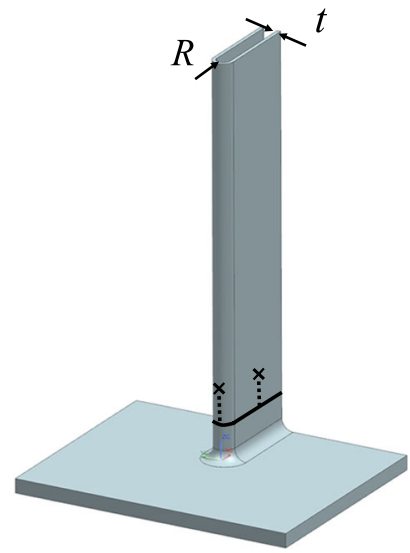

Fig. 13 Simplified CAD model of the product to be welded

An increase in the temperature ratio acts as an indicator that the weld pool (melted zone) is growing. In addition, higher temperatures lead to higher material viscosities. Consequently, larger and more viscous weld pools result in larger drops and worse overlap, along with higher risks of incomplete penetration.

Welding simulation setting The welding parameters input to the simulation (speed, voltage, current, Goldak parameters) have been based on historical production data and input from welding experts in the area. The values of the parameters mentioned have been kept constant for each thickness (for each column in Table 4, the same parameters were used). The reason is to study the effect of the radius on the melted pool increase per thickness. This choice is further elaborated on in the Discussion section.

Figure 13 shows a simplified model of the product created for the study. The black line represents the weld contour. The two nodes selected to extract the temperature values ( $T_{\text {curved }}$ and $\left.T_{\text {straight }}\right)$ are indicated in the figure as black crosses. The former node is located in the curved area and 


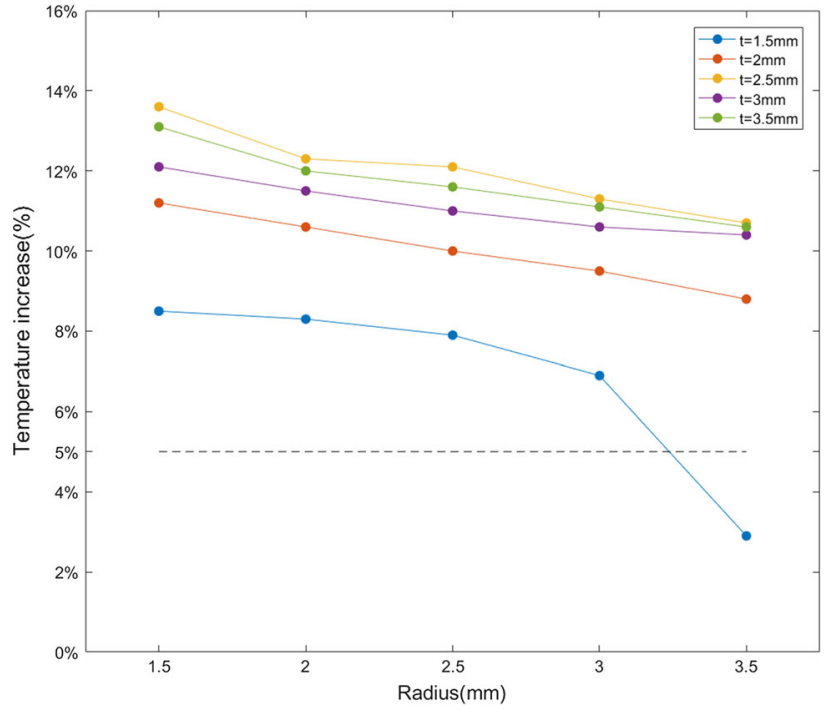

Fig. 14 Relationship between the design parameters (radius and thickness) and temperature increase

Table 5 Temperature ratio for the design space selected

\begin{tabular}{|c|c|c|c|c|c|c|}
\hline & \multicolumn{5}{|c|}{ Thicknesses } \\
\hline & & 1.5 & 2 & 2.5 & 3 & 3.5 \\
\hline \multirow[t]{5}{*}{ Radii } & 1.5 & 1.085 & 1.112 & 1.136 & 1.121 & 1.131 \\
\hline & 2 & 1.083 & 1.106 & 1.123 & 1.115 & 1.120 \\
\hline & 2.5 & 1.079 & 1.100 & 1.121 & 1.110 & 1.116 \\
\hline & 3 & 1.069 & 1.095 & 1.113 & 1.106 & 1.111 \\
\hline & 3.5 & 1.029 & 1.088 & 1.107 & 1.104 & 1.106 \\
\hline \multicolumn{2}{|c|}{ Straight } & 1 & 1 & 1 & 1 & 1 \\
\hline
\end{tabular}

the latter is located in the straight area, both at same distance from the weld interface.

Welding simulation results Table 5 contains the values of the temperature ratio for each of the product variants studied.

In the graph presented in Fig. 14, results from the table are plotted to show the effect of the radius on the temperature ratio for each thickness. The temperature ratio is expressed as a percentage increase.

Based on information from production, a temperature increase above 5\% indicates that the weld pool size has grown enough to lead to dropping problems, causing overlap (thus, not fulfilling requirements, see Fig. 12). The smallest thickness $(t=1.5 \mathrm{~mm})$ results in a temperature increase that drops under $5 \%$ for the largest radius $(3.5 \mathrm{~mm})$. However, for smaller radii, the temperature increase is higher and thus, the effects on the weld pool size are more significant. Therefore, as the radius becomes smaller, the design concept becomes more sensitive and less robust. The temperature increase for thickness $t=2.5 \mathrm{~mm}$ are higher than for $t=3$ and $t=3.5 \mathrm{~mm}$, owing to a drop of the welding speed value needed for thicker materials. Even so, the trends show that the temperature increase is too high (over 5\%) to ensure weld quality. Only for thicknesses $(t=1.5 \mathrm{~mm})$ and values of radii around $3.5 \mathrm{~mm}(3.50 \pm 3 \mathrm{~mm})$, there risk of welding failure is minor.

The results from the welding simulations are consistent with the qualitative assessment presented in Table 3. Table 3 shows that if the value of the radius decreases, there is a higher probability of overlap on the top side and incomplete joint penetration, which corresponds to a higher probability of quality failure of the weld bead geometry.

\section{Discussion}

\subsection{Case study results}

In the case study, the relationship between design parameters (radius and thickness) and welding failure modes (overlap and incomplete joint penetration) has been studied by evaluating the temperature ratio increase in the straight and curved areas of a TEC blade. The increase of temperature in the curved area of the weld contour can be mitigated by some actions. Such action is to decrease the power and heat effect in that area by tuning welding parameters. However, a rapid and drastic reduction of power may lead to incomplete penetration problems. In addition, welding parameter settings rely on operator skills and experience. Thus, changing welding parameter values along the weld path would increase the demands on the welding operation itself, increasing the sensitivity of the concept. For this reason, the welding process parameters have been kept constant along the weld path with the objective of finding the values of the design parameters $\left(q_{D E S I G N}\right)$ that make the concept more robust.

To qualify the results of the case study, Fig. 14 was shown to the same welding engineers who were previously interviewed (see Table 1). They confirmed that the results corresponded with the experts' judgement.

\subsection{WCAM method validation}

In an effort to validate the proposed WCAM method, a short questionnaire was sent to three company employees representing key roles within the multidisciplinary design process (a KBE expert, a DFM expert and a Robust Design expert). Three questions were asked relating to the usefulness, applicability and limitations of the WCAM method. The first two questions asked whether the WCAM method can support design analysis and whether it supports virtual design, and all three respondents confirmed that it accomplishes both of these needs. The third question asked about the potential limitations of this approach, and some were identified. One potential concern may be the mechanisms needed to keep knowledge and information up-to-date to account for 
technological advancements in welding equipment and new materials. In addition, due to the complexity of the problem and the large number of factors influencing the welding outcome quality, some prioritization based on experience and expertise is likely still needed. Nevertheless, the future incorporation of this approach in a virtual environment linked to computerized tools could possibly handle these limitations.

\subsection{General discussion and future work}

By applying the method proposed in this particular case study, first designers can identify thickness and radius as the design parameters critical to the welding operation to ensure the quality of the weld bead geometry, regarding incomplete joint penetration and overlap on the top side. Second, designers can assess the thickness and radius values that have the highest risk of failure.

The qualitative guidelines provided in the WCAM method and described in Section 3 increase our general understanding of the connection between the possible failure modes that can occur during welding and the causes related to product geometry and design parameters. The combination of these guidelines and quantitative assessments (welding simulations in the Case Study) provides objective information to support the multidisciplinary design process. In addition, this information can be collected in capability data bases and be reused in future projects. However, there is still a lack of simulation methods to produce welding capability data as shown in the overview of methods presented in Table 3. Some failure modes and related design parameters $\left(q_{D E S I G N}\right)$ present a lack of virtual tools to quantify their relationship. Most methods relate to physical experimentation. However, when it comes to assessing the capability of many geometrical variants, such an effort may require a large number of testing samples which might be costly. This indicates a need for virtual assessment methods and for planning systematic experimentation to produce data that can be reused in future projects. Therefore, to ensure quality earlier during the design process and search within the design space for solutions with acceptable welding capability levels, expert knowledge must be structured and automatized. Patterns and engineering rules need to be extracted from specialized information about welding problems, know-how, inspection and simulation data. However, to generate such "interactive engineering rules", there is first a need to decompose all potential quality problems during welding that could cause variation outside tolerance limits. The next step is to identify what design parameters cause those problems. Having identified "if $X$ then $Y$ " rules, the next step is to quantify this relationship to be able to generate interactive engineering rules. This step-based approach is prescribed by the paper's method.

The method proposed in this paper, the WCAM method, presents a comprehensive list of failure modes related to the quality of the welding operation outcome. This provides designers with support to identify and assess important design issues to ensure product quality when designing high performance product geometries that will be welded.In this method, a number of solutions are proposed for any given problem or situation, where some solutions are based on simulations and some are not. When possible, combinations of simulations (variation and welding simulation) can be used to generate data to create interactive engineering rules, as shown in the case study. However, other weld quality problems will require physical experimentation to generate data for modelling. All in all, the proposed method establishes the structure and the basis to generate the data and extract interactive engineering rules, which will lead to more virtual development in the future.

Therefore, it can be concluded that the WCAM method represents a new way to perform DFM analysis with a manufacturing quality focus, replacing traditional DFM tools that focus purely on time or cost. However, the assessment provided by this method is only one part of the multidisciplinary design exploration process. For integrated products, the geometry is highly linked to product performance. A modification in the target value and tolerances of a design parameter to ensure welding quality might affect product performance and cost. For instance, in the case study, increasing the value of the radius would lead to a lower probability of overlap and incomplete joint penetration. In contrast, a wider radius of the turbine blade would, in some cases, decrease aerodynamic performance.

In multidisciplinary design, requirements and tolerances in design parameters need to be set not only to ensure welding output quality but also to ensure requirements from other disciplines such as aerodynamics, product life, product weight and cost. The welding capability space must be well understood and quantifiable to support trade-offs with other disciplines.

Future work can focus on adapting and incorporating the data and information generated by this method into a multidisciplinary design analysis and optimization (MDAO) environment.Once interactive engineering rules are generated, the method could be fully automated and incorporated in a virtual environment to support the analysis of the design space. By incorporating this method in MDAO, product variants could be evaluated quantitatively across the full range of product objectives and constrains. Furthermore, support for welding method selection could also be tested.

\section{Conclusions}

Current DFM selection tools and manufacturability assessment methodologies rely on the existence of databases that contain knowledge about the limitations of the different 
materials and manufacturing processes in relation to certain product geometries. However, for welding, these capability databases do not exist. Traditional DFM guidelines do not support welding recommendations at a level of detail needed to make appropriate decisions during the product design phase. In addition, research on Welding Engineering mainly focuses on welding parameters and how they affect welding output. Physical and virtual welding experiments can be conducted for single geometries, but variants are generally not tested or compared. Thus, no support is given on how the product geometry space affects the output of the welding process, which hinders design space exploration during multidisciplinary design.

In this paper, a method is proposed to support the systematic identification and assessment of design issues related to product geometry critical to the welding process. The Welding Capability Assessment Method (WCAM) consists of two steps. The first step connects the welding outcome to product quality performance, setting requirements and tolerances on the welding output. The second step then identifies and assesses the product design parameters that cause variation in that welding outcome and may impair product quality performance. The objective is to set the target values and tolerances of key design parameters to avoid welding failures, ensuring product performance quality upfront in the design process.. By the use of failure modes, the focus of the method has been on quality rather than on time and cost. Thus, the method proposed, WCAM method, contributes to DFM tools for welded aerospace components within the framework of design for quality and variation risk management.

By applying this method, cross-functional teams can first generate information about the welding capabilities to support designers with interactive engineering rules during the design exploration process, and second, support the tolerancing process.

Due to the complexity of the phenomena occurring during the welding operation and the many factors affecting welding output, it has been demonstrated, through an industrial application, that a combination of qualitative and quantitative assessment (welding simulations) provides a more complete support to designers when making decisions.

The method proposed in this paper represents a step forward from the qualitative guidelines and expert judgments about the welding difficulties towards a more rigorous quantitative approach, supporting virtual design.

Acknowledgements This study was carried out at the Wingquist Laboratory VINN Excellence Centre within the Area of Advance Production at Chalmers University of Technology in Gothenburg, Sweden. It has received support from the Swedish Governmental Agency of Innovation Systems (VINNOVA) and the NFFP6 program. The support is gratefully acknowledged.
Open Access This article is distributed under the terms of the Creative Commons Attribution 4.0 International License (http://creativecomm ons.org/licenses/by/4.0/), which permits unrestricted use, distribution, and reproduction in any medium, provided you give appropriate credit to the original author(s) and the source, provide a link to the Creative Commons license, and indicate if changes were made.

\section{References}

1. Runnemalm, H., Tersing, H., Isaksson, O.: Virtual Manufacturing of Light Weight Aero Engine Components. In: Proc ISABE (2009)

2. Tasalloti, H., Eskelinen, H., Kah, P., Martikainen, J.: An integrated DFMAPDM model for the design and analysis of challenging similar and dissimilar welds. Mater. Des. 89, 421-431 (2016)

3. Raja, V.: on integrated product architectures: Representation, modelling and evaluation. Chalmers University of Technology (2016)

4. Forslund, A.: Uncertainty and Robustness in Aerospace Structures. Chalmers University of Technology (2016)

5. Shukor, S.A., Axinte, D.: Manufacturability analysis system: issues and future trends. Int. J. Prod. Res. 47(5), 1369-1390 (2009)

6. Boothroyd, G., Dewhurst, P., Knight, W.A.: Product design for manufacture and assembly, vol. 58, Second. Revised and Expanded ed. Marcel Dekker, Inc, New York (2002)

7. Boothroyd, G., Dewhurst, P.: Product design for assembly. Boothroyd Dewhurst Incorporated, (1987)

8. Boothroyd, G., Radovanovic, P.: Estimating the cost of machined components during the conceptual design of a product. CIRP Ann. Manuf. Technol. 38(1), 157-160 (1989)

9. Poli, C.: Design for manufacturing: a structured approach, vol. 1. Butterworth-Heinemann, Oxford (2001)

10. Swift, K.G., Booker, J.D.: Process selection: from design to manufacture. Butterworth-Heinemann, Oxford (2003)

11. Bralla, J.G.: Design for Manufacturability Handbook. McGrawHill, New York (1999)

12. LeBacq, C., Brechet, Y., Shercliff, H., Jeggy, T., Salvo, L.: Selection of joining methods in mechanical design. Mater. Des. 23(4), 405416 (2002)

13. Maropoulos, P., Yao, Z., Bradley, H., Paramor, K.: An integrated design and planning environment for welding: Part 1: product modelling. J. Mater. Process. Technol. 107(1), 3-8 (2000)

14. Stolt, R., Andr, S., Elgh, F., Andersson, P.: Manufacturability assessment in the conceptual design of aircraft enginesbuilding knowledge and balancing trade-offs. In: IFIP International Conference on Product Lifecycle Management, pp. 407-417 Springer (2015)

15. Ibrahim, I.H., Chassapis, C.: An interactive variation risk management environment to assess the risk of manufacturing variations. Int. J. Interactive Des. Manuf. (IJIDeM), 1-12 (2016)

16. Madrid, J.; Vallhagen, J.; Söderberg, R.; Wärmefjord, K.: Enabling reuse of inspection data to support robust design: a case in the aerospace industry. In: 14th CIRP Conference on Computer Aided Tolerancing (CAT) (2016)

17. Kwon, Y., Wu, T., Saldivar, J.O.: SMWA: a CAD-based decision support system for the efficient design of welding. Concurr. Eng. 12(4), 295-304 (2004)

18. Widener, C.A., Burford, D.A., Jurak, S.: Effects of tool design and friction stir welding parameters on weld morphology in aluminum alloys. In: Materials Science Forum, pp. 1261-1266. Trans Tech Publ (2010)

19. Wärmefjord, K., Söderberg, R., Lindkvist, L.: Strategies for optimization of spot welding sequence with respect to geometrical variation in sheet metal assemblies. In: ASME 2010 International Mechanical Engineering Congress and Exposition, pp. 569-577. American Society of Mechanical Engineers (2010) 
20. Sandberg, M., Tyapin, I., Kokkolaras, M., Lundbladh, A., Isaksson, O.: A knowledge-based master model approach exemplified with jet engine structural design. Comput. Ind. 85, 31-38 (2017)

21. Sobek, D.K., Ward, A.C., Liker, J.K.: Toyota's principles of setbased concurrent engineering. Sloan Manag. Rev. 40(2), 67-84 (1999)

22. Ali, F., Tzanidakis, K., Goulos, I., Pachidis, V., d'Ippolito, R.: Design space exploration and optimization of conceptual rotorcraft powerplants. J. Eng. Gas Turbines Power 137(12), 121701 (2015)

23. Andreasen, M.M., Kähler, S., Lund, T.: Design for assembly. IFS, (1983)

24. Harik, R.F., Sahmrani, N.: DFMA+, a quantitative DFMA methodology. Comput. Aided Des. Appl. 7(5), 701-709 (2010)

25. Sanders, D., Chai Tan, Y., Rogers, I., Tewkesbury, G.E.: An expert system for automatic design-for-assembly. Assem. Autom. 29(4), 378-388 (2009)

26. Elgh, F.: Computer-supported design for producibility: principles and models for system realisation and utilisation (2007)

27. Sandberg, M.: Design for manufacturing: methods and applications using knowledge engineering (2007)

28. Pahl, G., Beitz, W.: Engineering Design: A Systematic Approach, 2nd edn. Springer, London (1996)

29. Jenney, C.L., O'Brien, A.: Welding Handbook, Volume 1 - Welding Science and Technology (9th edition). American Welding Society (AWS). In. (2001)

30. Olson, D.L., Siewert, T.A., Liu, S., Edwards, G.R.: ASM Handbook: Welding, Brazing, and Soldering, vol. 6. Asm Intl, Ohio (1993)

31. Miles, B.: Design for assemblya key element within design for manufacture. In: Proceedings of the Institution of Mechanical Engineers, Part D: Journal of Automobile Engineering 203(1), 29-38 (1989)

32. Schreve, K., Schuster, H., Basson, A.: Manufacturing cost estimation during design of fabricated parts. In: Proceedings of the Institution of Mechanical Engineers, Part B: Journal of Engineering Manufacture 213(7), 731-735 (1999)

33. Vallhagen, J., Madrid, J., Söderberg, R., Wärmefjord, K.: An approach for producibility and DFM-methodology in aerospace engine component development. Proc. CIRP 11, 151-156 (2013)

34. Madrid, J., Söderberg, R., Vallhagen, J., Wärmefjord, K.: Development of a conceptual framework to assess producibility for fabricated aerospace components. Proc. CIRP 41, 681-686 (2016)

35. Thornton, A.C.: Variation risk management: focusing quality improvements in product development and production. Wiley, New York (2004)

36. Etienne, A., Mirdamadi, S., Mohammadi, M., Malmiry, R.B., Antoine, J.-F., Siadat, A., Dantan, J.-Y., Tavakkoli, R., Martin, P.: Cost engineering for variation management during the product and process development. International Journal on Interactive Design and Manufacturing (IJIDeM), 1-12 (2016)

37. Subramaniam, B.L., Ulrich, K.T.: Producibility analysis using metrics based on physical process models. Res. Eng. Des. 10(4), 210-225 (1998)

38. Hubka, V., Eder, W.E.: Theory of Technical Systems : A Total Concept Theory for Engineering Design. Springer, Berlin (1988)
39. Söderberg, R., Lindkvist, L., Dahlström, S.: Computer-aided robustness analysis for compliant assemblies. J. Eng. Des. 17(5), 411-428 (2006)

40. Mørup, M.: Design for Quality. University of Denmark, Techn (1993)

41. Dantan, J., Hassan, A., Etienne, A., Siadat, A., Martin, P.: Information modeling for variation management during the product and manufacturing process design. Int. J. Interact. Des. Manuf. (IJIDeM) 2(2), 107-118 (2008)

42. Mirdamadi, S., Siadat, A., Dantan, J.-Y., Roucoules, L.: An adaptive approach to failure modes and effects analysis for Computer-Aided Inspection Planning. In: Industrial Engineering and Engineering Management (IEEM), International Conference, pp. 2179-2183. (2012)

43. Mathieu, L., Marguet, B.: Integrated design method to improve producibility based on product key characteristics and assembly sequences. CIRP Ann. Manuf. Technol. 50(1), 85-88 (2001)

44. Taguchi, G., Chowdhury, S., Wu, Y.: Taguchi's Quality Engineering Handbook. Wiley, New York (2005)

45. O'Brien, A., Guzman, C.: American Welding Society, Welding Handbook Welding Processes. In. part, (2007)

46. Pahkamaa, A., Wärmefjord, K., Karlsson, L., Söderberg, R., Goldak, J.: Combining variation simulation with welding simulation for prediction of deformation and variation of a final assembly. J. Comput. Inf. Sci. Eng. 12(2), 021002 (2012)

47. Jonsson, B., Samuelsson, J., Marquis, G.: Development of weld quality criteria based on fatigue performance. Weld. World 55(11/12), 79-88 (2011)

48. Steffenburg-Nordenström, J., Larsson, M.: Simulation of the influence of forming on residual stresses and deformations after welding and heat treatment in Alloy 718. In: 11th World Congress on Computational Mechanics (WCCM XI) 5th European Conference on Computational Mechanics (ECCM V) 6th European Conference on Computational Fluid Dynamics (ECFD VI), pp. 1657-1666 (2014)

49. Wärmefjord, K., Söderberg, R., Ericsson, M., Appelgren, A., Lundbäck, A., Lööf, J., Lindkvist, L., Svensson, H.-O.: Welding of non-nominal geometriesphysical tests. Proc. CIRP 43, 136-141 (2016)

50. Hammersberg, P., Olsson, H.: Proactive control of weld dimensions in robotised MAG welding. In: Proceedings of the Second Swedish Conference on Design and Fabrication of Welded Structures (2013)

51. Landahl, J., Levandowski, C., Johannesson, H., Isaksson, O. Assessing producibility of product platforms using set-based concurrent engineering. In: Transdisciplinary Engineering: Crossing Boundaries 2016, pp. 35-44. Ios Press

52. Carlson, J.S., Spensieri, D., Söderberg, R., Bohlin, R., Lindkvist, L.: Non-nominal path planning for robust robotic assembly. J. Manuf. Syst. 32(3), 429-435 (2013) 